\title{
Success and Complication Rates After Sacral Neuromodulation for Fecal Incontinence and Constipation: A Single-center Follow-up Study
}

\author{
Bernhard Widmann, ${ }^{1}$ Christian Galata, ${ }^{2}$ Rene Warschkow, ${ }^{1,3}$ Ulrich Beutner, ${ }^{1}$ Önder Ögredici, ${ }^{1}$ Franc H Hetzer, ${ }^{4}$ Bruno M Schmied, ${ }^{1}$ \\ Stefan Post, ${ }^{2}$ and Lukas Marti ${ }^{1,2 *}$ \\ ${ }^{1}$ Department of General, Visceral, Endocrine and Transplantation Surgery, Kantonsspital St. Gallen, Switzerland; ${ }^{2}$ Department of Surgery, \\ University Medical Center Mannheim, University of Heidelberg, Mannheim, Germany; ${ }^{3}$ Institute of Medical Biometry and Informatics, University \\ of Heidelberg, Germany; and ${ }^{4}$ Department of Surgery, Spital Linth, Uznach, Switzerland
}

\section{Background/Aims}

The aim of this study was to evaluate the sustainability of sacral neuromodulation (SNM) success in patients with fecal incontinence (FI) and/or constipation.

\section{Methods}

This is a retrospective analysis of a prospective database of patients who received SNM therapy for $\mathrm{Fl}$ and/or constipation between 2006 and 2015. Success rates, complications and reintervention rates were assessed after up to 10 years of follow-up.

\section{Results}

Electrodes for test stimulation were implanted in 101 patients, of whom 79 (78.2\%) received permanent stimulation. The mean follow-up was $4.4 \pm 3.0$ years. At the end of follow-up, 57 patients $(72.2 \%)$ were still receiving SNM. The 5-year success rate for $\mathrm{FI}$ and isolated constipation was $88.2 \%$ (95\% confidence interval $[\mathrm{Cl}], 80.1-97.0 \%)$ and $31.2 \%(95 \% \mathrm{Cl}, 10.2-95.5 \%)$, respectively $(P<$ 0.001). In patients with $\mathrm{Fl}$, involuntary evacuations per week decreased $>50 \%$ in $76.1 \%$ of patients $(95 \% \mathrm{Cl}, 67.6-86.2 \%)$ after 5 years. A lead position at $\$ 3$ was associated with an improved outcome $(P=0.04)$. Battery exchange was necessary in 23 patients $(29.1 \%)$, with a median battery life of 6.2 years. Reinterventions due to complications were necessary in 24 patients (30.4\%). For these patients, the 5-year success rate was $89.0 \%(95 \% \mathrm{Cl}, 75.3-100.0 \%)$ compared to $78.4 \%(95 \% \mathrm{Cl}, 67.2-91.4 \%)$ for patients without reintervention.

\section{Conclusions}

SNM offers an effective sustainable treatment for FI. For constipation, lasting success of SNM is limited and is thus not recommended. Reinterventions are necessary but do not impede treatment success.

(J Neurogastroenterol Motil 2019;25:159-170)

Key Words

Constipation; Electric stimulation; Fecal incontinence; Sacral nerve stimulation; Sacral neuromodulation

Received: September 1, 2018 Revised: September 28, 2018 Accepted: October 9, 2018

(.) This is an Open Access article distributed under the terms of the Creative Commons Attribution Non-Commercial License (http://creativecommons. org/licenses/by-nc/4.0) which permits unrestricted non-commercial use, distribution, and reproduction in any medium, provided the original work is properly cited.

${ }^{*}$ Correspondence: Lukas Marti, MD

Department of General, Visceral, Endocrine and Transplantation Surgery, Kantonsspital St. Gallen, CH-9007 St. Gallen, Switzerland Tel: +41-71-494-1339, Fax: +41-71-494-2886, E-mail: lukas.marti@kssg.ch 


\section{Introduction}

Defecation disorders such as fecal incontinence (FI) and constipation are common and often underreported. The estimated prevalence of constipation in the general population is approximately $15 \%$, while the estimated prevalence is $6-11 \%$ for FI. ${ }^{1,2}$ Fecal disorders are accompanied by embarrassment, shame and depression. This leads to impairment in patients' quality of life (QoL), as defecation habits tend to control both personal and social lifestyles. In addition, FI and constipation impose a significant healthcare burden. ${ }^{3}$

Over the last 2 decades, neuromodulation has become an accepted treatment for FI and to some extent also for constipation. Sacral neuromodulation (SNM) is a minimally invasive treatment involving continuous, pulsating electrical stimulation of the sacral nerves. SNM is therefore also called sacral nerve stimulation (SNS). The exact mechanism of action of SNM is not yet fully understood. Studies have demonstrated both a direct effect on the sphincter muscle $^{4-6}$ and modulation of spinal and supraspinal functions. ${ }^{7,8}$

The short- and mid-term success of SNM in patients with FI has been demonstrated in several studies. ${ }^{9-11}$ Recently, studies with long-term follow-up have shown a lasting effect. ${ }^{12-14}$ Data regarding constipation are rare, particularly data with a long-term followup. Despite initial success, the role of SNM for constipation is still debated. ${ }^{15,16}$ A further challenge is to investigate the long-term adverse events and the efforts required to maintain SNM. Surgical reintervention rates are high, increase over time and are likely to be underreported. $^{17-19}$

The aim of this study was to assess the sustainability of SNM success in patients with FI and constipation. Additionally, the rates of adverse events and reinterventions were recorded, and the effects of adverse events and reintervention on treatment success were evaluated.

\section{Materials and Methods}

\section{Study Design and Participants}

This is a retrospective, single center analysis of a prospectively maintained database.

All patients who underwent invasive neuromodulation ( $\mathrm{n}=$ 115 ) at the surgical department of the Kantonsspital St. Gallen in Switzerland from February 2006 to October 2015 were prospectively registered in the Swiss Registry of Sacral Neuromodulation. The study was approved by the Institutional Review Board at the Ethikkommission Ostschweiz (BASEC No. 2016-00585) and was registered at clinicaltrials.gov with the identifier NCT02836717.

The patients were informed at the start of the therapy that their data would be recorded in a registry. They were asked for their consent for registering, analyzing and performing a quality assessment of their data. After obtaining informed consent, patients older than 18 years of age who received SNM therapy due to chronic FI or constipation after unsuccessful conservative treatment were included in the study. Some patients underwent previous surgical treatment such as sphincteroplasty $(n=11)$, levatoroplasty $(n=1)$, or rectopexy $(n=2)$. Two patients were excluded because they did not provide consent for data evaluation. Ten patients were excluded because they received pudendal nerve stimulation, and 2 patients were excluded because the indication for SNM therapy was pelvic pain without FI or constipation.

\section{Study Procedures}

All patients underwent a systematic workup before they were enrolled in SNM screening. At the baseline visit, each patient's underlying diagnosis and previous therapies were documented. Furthermore, an endoanal ultrasound and an anorectal manometry were part of the workup. Both investigations could not be recorded in the SNM registry and for this reason were not assessed. For patients with FI, the Wexner score (Cleveland clinic incontinence score), ${ }^{20}$ the number of involuntary evacuations per week and the ability to defer defecation were recorded. Patients were asked to complete the Fecal Incontinence Quality of Life (FIQL) questionnaire. ${ }^{21}$ Patients with constipation recorded their bowel movements in a diary. Furthermore, colon transit time was routinely assessed by radiography. Because these data could not be recorded in the SNM registry, the therapeutic success for constipation was only assessed by subjective symptom improvement.

SNM therapy was initiated by implanting a permanent electrode (tined lead; Medtronic, Minneapolis, Minnesota, USA). If possible, nerve evaluation at both sacral foramina $3(\mathrm{~S} 3)$ and $\mathrm{S} 4$ was performed. The electrode was implanted at the foramen with the best sensory or motor response. During the screening phase, the electrode was connected to an extracorporeal stimulator and was adjusted weekly. If constipation or FI symptoms were reduced by more than $50 \%$, the screening was considered successful and an internal permanent pulse generator (IPG) (InterStim I or II; Medtronic) was implanted. SNM therapy was considered successful if it was ongoing and the patient reported sustained subjective symptom improvement in either FI or constipation. The patient's subjective evaluation of symptom improvement was the only factor that was used to define success. Further information was used to 
objectify but not define SNM success, including the Wexner score, the number of involuntary evacuations per week, the ability to defer defecation and the FIQL.

Follow-up occurred regularly 1, 3, and 6 months after implantation, followed by annual evaluations. During each visit, the battery status, electrode function, and current programming were evaluated and adjusted if necessary. Additional therapies and subjective symptom improvements were recorded, and an FIQL questionnaire was distributed. For all patients with FI, the Wexner score, the number of involuntary evacuations per week and the ability to defer defecation were documented. Finally, adverse events and reinterventions were recorded.

If a patient missed a follow-up visit, the FIQL questionnaire was sent by mail, and other data were obtained by telephone interview if possible.

\section{Statistical Methods}

Statistical analyses were performed using $\mathrm{R}$ statistical software (www.r-project.org). A 2 -sided $P$-value $<0.05$ was considered statistically significant. Continuous data are expressed as the mean \pm SD or $95 \%$ confidence interval (CI) and as medians with ranges. The Chi-square test, Student's $t$ test, and the Wilcoxon test were used to compare proportions and continuous variables. In the regression analysis, all $P$-values were computed by likelihood ratio tests. Wald-type CIs were estimated. Missing data were imputed using the last observation carried forward, and the random survival forest method. ${ }^{22}$ Successfully sustained SNM therapy was the primary outcome. Success was assessed from the time of implantation until permanent discontinuation of SNM therapy. If SNM therapy was discontinued due to reasons unrelated to the SNM procedure, these events were censored. Permanent SNM discontinuation was assessed by a Kaplan-Meier analysis. Univariate and multivariate Cox regression analysis were performed with adjustment for age, sex, existence and cause of incontinence, and lead position. Based on the Akaike information criterion, irrelevant variables were eliminated from the full Cox regression model by backward variable selection. To assess subjective outcomes in the questionnaire over time, a locally weighted scatterplot smoothing (LOWESS) regression analysis was performed. ${ }^{23}$

\section{Results}

\section{Patient Characteristics}

In this trial, 101 patients ( 82 females) were included. The median age was 64 (range, 18-81) years. The indication for SNM therapy was constipation in 16 patients (15.8\%), FI in 73 (72.3\%), and both FI and constipation in 12 (11.9\%), with FI being the leading symptom. The patient characteristics are summarized in Table 1. Patients with constipation were classified as either slow transit $(n=11)$, outlet obstruction $(n=15)$ or both outlet obstruction and slow transit $(n=2)$. There was no difference in the success of the screening or in lasting success between the subgroups with constipation $(P>0.05)$. Subgroups of constipation were therefore not further differentiated.

\section{Screening Success}

Definitive SNM implantation was performed in 79 patients (78.2\%) (Table 1). Screening was successful in $100 \%$ of patients with both FI and constipation $(\mathrm{n}=12), 80.8 \%$ (59/73) with FI, and $50 \%(8 / 16)$ with constipation. Isolated constipation $(P=0.004)$ was the only negative predictor for screening success.

\section{Sacral neuromodulation Success Over Time}

At the end of follow-up, 57 patients (72.2\%) had successfully sustained SNM therapy. The mean follow-up was $4.4 \pm 3.0$ years, and the median follow-up was 4.2 (0.1-10.0) years. The general 5-year and 7-year SNM success rates were 75.1\% (95\% CI, 64.8$86.7 \%$ ) and $69.8 \%$ (95\% CI, 58.5-83.2\%), respectively. The SNMspecific (censoring 4 patients for discontinuation due to reasons unrelated to SNM therapy) 5-year and 7-year success rates were 81.7\% (95\% CI, 72.6-91.9\%) and 76.1\% (95\% CI, 65.2-88.7\%), respectively (Fig. 1A). All the following success rates describe specific SNM success. The 5-year success rates were $87.3 \%$ (95\% CI, 78.1-97.6\%) for FI alone, 31.2\% (95\% CI, 10.2-95.5\%) for constipation, and $91.7 \%$ (95\% CI, 77.3-100.0\%) for patients with both FI and constipation. The yearly rates for SNM success are shown in Table 2. When analyzed jointly, 88.2\% (95\% CI, 80.1-97.0\%) of FI patients with or without constipation had sustained successful therapy for over 5 years, and $85.3 \%$ (95\% CI, 76.1-95.7\%) of these patients had sustained successful therapy for over 7 years.

The 5-year success rates for the different etiologies of FI were 84.4\% (95\% CI, 71.5-99.8\%) for FI caused by a sphincter defect $(\mathrm{n}=29), 100.0 \%$ (95\% CI, 54.1-100.0\%) for idiopathic FI $(\mathrm{n}=$ 6), $100.0 \%$ (95\% CI, 59.0-100.0\%) for multifactorial FI ( $\mathrm{n}=7$ ), $87.5 \%$ (95\% CI, 67.3-100.0\%) for FI due to a neurogenic disorder $(\mathrm{n}=11)$, and $83.7 \%$ (95\% CI, 64.5-100.0\%) for FI after pelvic surgery $(\mathrm{n}=18)$. There was no significant difference regarding the etiologies in patients with a combination of FI and constipation compared to those with $\mathrm{FI}$ alone $(P=0.092)$. Of the 22 patients in 
Table 1. Patient Characteristics and Bias for Implantation

\begin{tabular}{|c|c|c|c|c|}
\hline Patient characteristics & $\begin{array}{c}\text { Total } \\
(\mathrm{n}=101)\end{array}$ & $\begin{array}{l}\text { Unsuccessful screening }^{\mathrm{a}} \\
\qquad(\mathrm{n}=22)\end{array}$ & $\begin{array}{l}\text { SNM implant } \\
\qquad(\mathrm{n}=79)\end{array}$ & $P$-value \\
\hline \multicolumn{5}{|l|}{ Sex } \\
\hline Female & $82(81.2 \%)$ & $16(72.7 \%)$ & $66(83.5 \%)$ & $0.251^{\mathrm{b}}$ \\
\hline Male & $19(18.8 \%)$ & $6(27.3 \%)$ & $13(16.5 \%)$ & \\
\hline Age (yr) & $61.6(13.5)$ & $64.2(12.6)$ & $60.9(13.8)$ & $0.299^{\mathrm{c}}$ \\
\hline \multicolumn{5}{|l|}{ Incontinence/constipation } \\
\hline Incontianence & $73(72.3 \%)$ & $14(63.6 \%)$ & $59(74.7 \%)$ & $0.004^{\mathrm{a}}$ \\
\hline Constipation & $16(15.8 \%)$ & $8(36.4 \%)$ & $8(10.1 \%)$ & \\
\hline Both & $12(11.9 \%)$ & $0(0.0 \%)$ & $12(15.2 \%)$ & \\
\hline \multicolumn{5}{|l|}{ Cause of incontinence } \\
\hline No incontinence & $16(15.8 \%)$ & $8(36.4 \%)$ & $8(10.1 \%)$ & $0.015^{\mathrm{d}}$ \\
\hline Sphincter defect & $31(30.7 \%)$ & $2(9.1 \%)$ & $29(36.7 \%)$ & \\
\hline Idiopathic & $6(5.9 \%)$ & $0(0.0 \%)$ & $6(7.6 \%)$ & \\
\hline Multifactorial & $9(8.9 \%)$ & $2(9.1 \%)$ & $7(8.9 \%)$ & \\
\hline Neurogenic disorder & $14(13.9 \%)$ & $3(13.6 \%)$ & $11(13.9 \%)$ & \\
\hline Pelvic surgery & $25(24.8 \%)$ & $7(31.8 \%)$ & $18(22.8 \%)$ & \\
\hline \multicolumn{5}{|l|}{ Type of incontinence } \\
\hline No incontinence & $16(15.8 \%)$ & $8(36.4 \%)$ & $8(10.1 \%)$ & $0.007^{\mathrm{d}}$ \\
\hline Nonneurogenic & $62(61.4 \%)$ & $9(40.9 \%)$ & $53(67.1 \%)$ & \\
\hline Neurogenic & $23(22.8 \%)$ & $5(22.7 \%)$ & $18(22.8 \%)$ & \\
\hline \multicolumn{5}{|l|}{ Constipation } \\
\hline No & $73(72.3 \%)$ & $14(63.6 \%)$ & $59(74.7 \%)$ & $0.306^{\mathrm{b}}$ \\
\hline Yes & $28(27.7 \%)$ & $8(36.4 \%)$ & $20(25.3 \%)$ & \\
\hline \multicolumn{5}{|l|}{ Type of constipation } \\
\hline No constipation & $73(72.3 \%)$ & $14(63.6 \%)$ & $59(74.7 \%)$ & $0.690^{\mathrm{d}}$ \\
\hline Outlet obstruction & $15(14.9 \%)$ & $4(18.2 \%)$ & $11(13.9 \%)$ & \\
\hline Slow transit & $11(10.9 \%)$ & $3(13.6 \%)$ & $8(10.1 \%)$ & \\
\hline Both & $2(2.0 \%)$ & $1(4.5 \%)$ & $1(1.3 \%)$ & \\
\hline \multicolumn{5}{|l|}{ Urinary incontinence } \\
\hline No & $78(77.2 \%)$ & $19(86.4 \%)$ & $59(74.7 \%)$ & $0.248^{\mathrm{b}}$ \\
\hline Yes & $23(22.8 \%)$ & $3(13.6 \%)$ & $20(25.3 \%)$ & \\
\hline \multicolumn{5}{|l|}{ Previous sphincteroplasty } \\
\hline No & $90(89.1 \%)$ & $20(90.9 \%)$ & $70(88.6 \%)$ & $0.759^{\mathrm{b}}$ \\
\hline Yes & $11(10.9 \%)$ & $2(9.1 \%)$ & $9(11.4 \%)$ & \\
\hline \multicolumn{5}{|l|}{ Other previous therapy } \\
\hline No & $81(80.2 \%)$ & $16(72.7 \%)$ & $65(82.3 \%)$ & $0.320^{\mathrm{b}}$ \\
\hline Yes & $20(19.8 \%)$ & $6(27.3 \%)$ & $14(17.7 \%)$ & \\
\hline \multicolumn{5}{|l|}{ Screening results } \\
\hline \multicolumn{5}{|l|}{ Lead position } \\
\hline S3 & $54(53.5 \%)$ & $12(54.5 \%)$ & $42(53.2 \%)$ & $1.000^{\mathrm{d}}$ \\
\hline S4 & $43(42.6 \%)$ & $9(40.9 \%)$ & $34(43.0 \%)$ & \\
\hline Both/unknown & $4(4.0 \%)$ & $1(4.5 \%)$ & $3(3.8 \%)$ & \\
\hline \multicolumn{5}{|l|}{ Complications during screening } \\
\hline No & $94(93.1 \%)$ & $20(90.9 \%)$ & $74(93.7 \%)$ & $0.652^{\mathrm{b}}$ \\
\hline Yes & $7(6.9 \%)$ & $2(9.1 \%)$ & $5(6.3 \%)$ & \\
\hline
\end{tabular}

whom therapy was terminated after implantation, 4 patients discontinued therapy for reasons not related to SNM (death, abdominoperineal resection due to cancer, no constipation after gastric bypass, and Hartmann's procedure because of perforated diverticulitis). In the remaining 18 patients, treatment termination was due to a lack or loss of efficacy $(n=15)$, infection $(n=1)$, pain/spinal infarct 
Table 1. Continued

\begin{tabular}{|c|c|c|c|c|}
\hline Patient characteristics & $\begin{array}{c}\text { Total } \\
(\mathrm{n}=101)\end{array}$ & $\begin{array}{l}\text { Unsuccessful screening }^{\mathrm{a}} \\
\qquad(\mathrm{n}=22)\end{array}$ & $\begin{array}{l}\text { SNM implant } \\
\quad(\mathrm{n}=79)\end{array}$ & $P$-value \\
\hline \multicolumn{5}{|l|}{ Subjective baseline data } \\
\hline Wexner score & $13.7(6.0)$ & $11.8(8.3)$ & $14.2(5.2)$ & $0.210^{\mathrm{c}}$ \\
\hline Involuntary evacuations per week & $10.6(21.4)$ & $7.0(5.5)$ & $11.6(23.9)$ & $0.118^{\mathrm{c}}$ \\
\hline \multicolumn{5}{|l|}{ Ability to defer defecation } \\
\hline$<1 \min$ & $66(65.3 \%)$ & $14(63.6 \%)$ & $52(65.8 \%)$ & $0.058^{\mathrm{d}}$ \\
\hline 1 to $<5 \mathrm{~min}$ & $13(12.9 \%)$ & $0(0.0 \%)$ & $13(16.5 \%)$ & \\
\hline 5 to $15 \mathrm{~min}$ & $1(1.0 \%)$ & $0(0.0 \%)$ & $1(1.3 \%)$ & \\
\hline$>15 \min$ & $21(20.8 \%)$ & $8(36.4 \%)$ & $13(16.5 \%)$ & \\
\hline FIQL lifestyle & $2.5(0.5)$ & $2.4(0.8)$ & $2.5(0.3)$ & $0.574^{\mathrm{c}}$ \\
\hline FIQL coping/behavior & $1.8(0.5)$ & $2.1(0.7)$ & $1.8(0.3)$ & $0.033^{\mathrm{c}}$ \\
\hline FIQL depression & $2.3(0.3)$ & $2.3(0.5)$ & $2.3(0.3)$ & $0.972^{\mathrm{c}}$ \\
\hline FIQL embarrassment & $2.3(0.4)$ & $2.6(0.5)$ & $2.2(0.4)$ & $0.008^{\mathrm{c}}$ \\
\hline
\end{tabular}

${ }^{a}$ Unsuccessful screening was defined as a less than $50 \%$ symptom improvement.

${ }^{\mathrm{b}} \mathrm{Chi}$-Square test.

' $t$ test.

${ }^{\mathrm{d}}$ Chi-Square test, Monte-Carlo simulated.

SNM, sacral neuromodulation; FIQL, fecal incontinence quality of life.

Values are expressed as $\mathrm{n}(\%)$ or mean (SD).

A

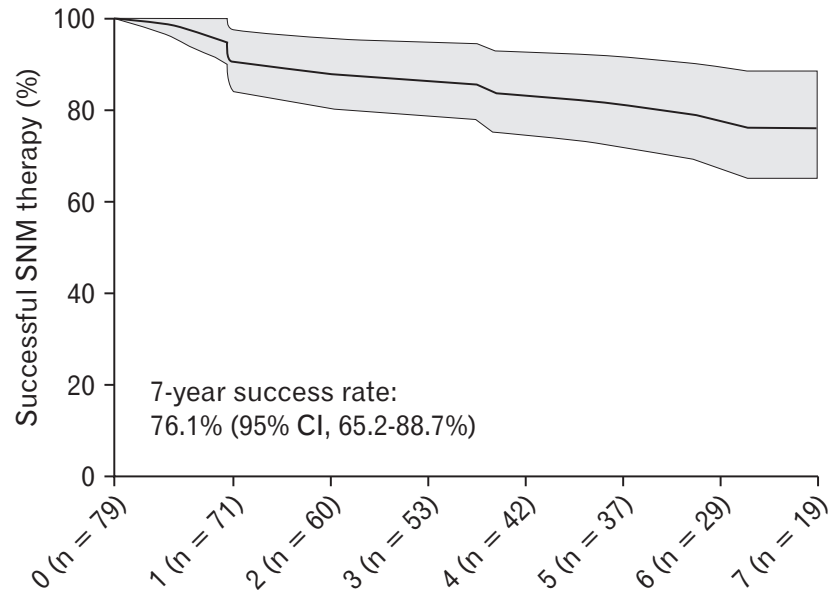

Years after implantation/patients at risk
B

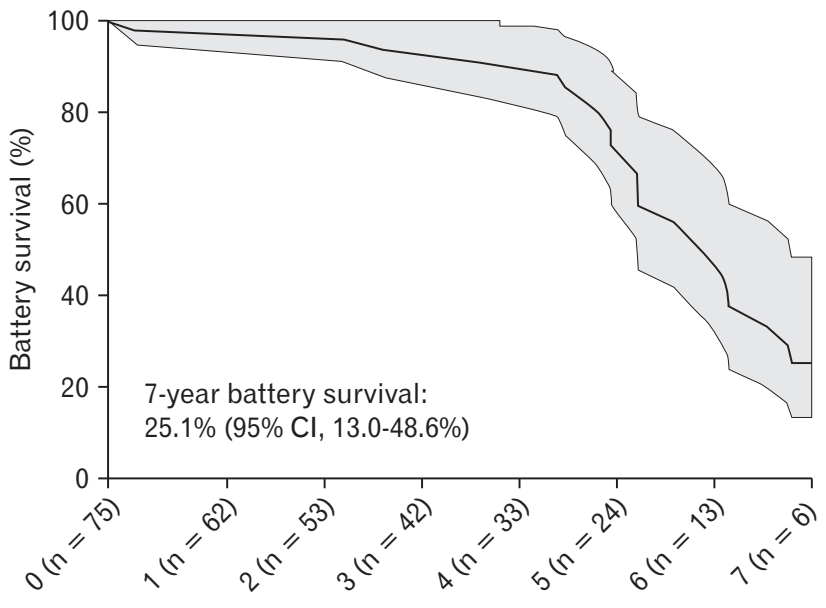

Years after implantation/patients at risk

Figure 1. Kaplan-Meier plots for sacral neuromodulation success and battery survival. (A) Sacral neuromodulation (SNM) success over time. Patients who discontinued SNM therapy due to reasons unrelated to SNM therapy were censored. (B) InterStim II battery life (InterStim I batteries were excluded). Kaplan-Meier plots including all patients (fecal incontinence and constipation) with an implanted permanent pulse generator with pointwise $95 \%$ CIs depicted. The number of patients at risk is given below each plot.

not related to SNM (due to spinal stenosis) ( $\mathrm{n}=1$ ), and withdrawn consent $(\mathrm{n}=1)$.

The rate of successful treatment on an intention-to-treat (ITT) basis was $70.1 \%$ (95\% CI, 60.3-81.4\%) for patients suffering from FI at 5 years and $67.9 \%(95 \% \mathrm{CI}, 57.7-79.9 \%)$ at 7 years including patients with unsuccessful screening and SNM termination for reasons unrelated to SNM therapy.
Figure 2 shows an ITT analysis comparing patients with isolated FI, isolated constipation and FI and constipation combined. The results for isolated constipation were significantly worse than those for isolated FI $(P<0.001)$. Furthermore, the outcomes for patients with a combination of FI and constipation were significantly better than those for isolated FI $(P=0.041)$. 


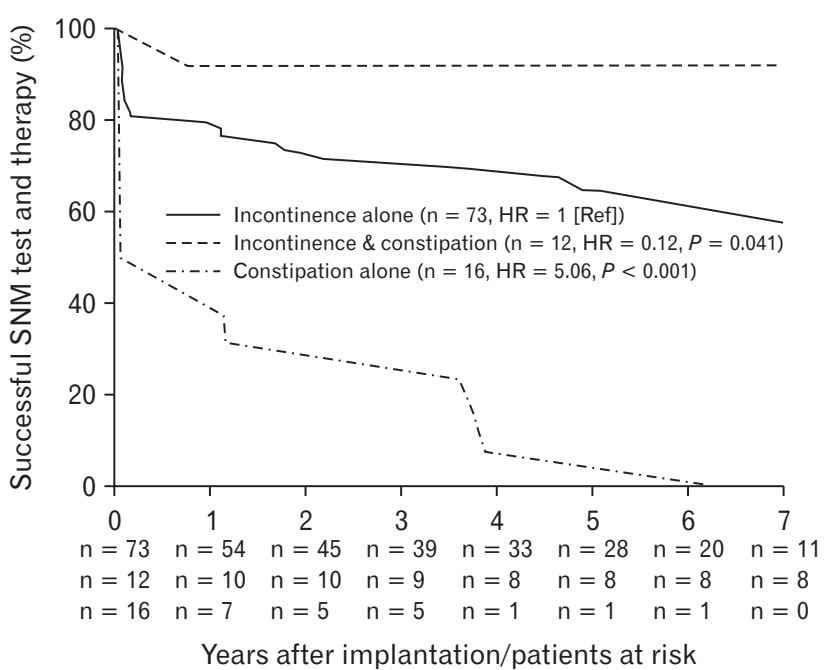

Figure 2. Successful sacral neuromodulation (SNM) test and therapy according to the indications. Intention-to-treat analysis comparing patients with isolated fecal incontinence (FI), isolated constipation and the combination of FI and constipation. Kaplan-Meier plot for successful SNM tests and therapy in the 3 subgroups. $P$-values were estimated with likelihood ratio tests. HR, hazard ratio; Ref, reference.

\section{Battery Life}

In $94.9 \%$ of patients ( $\mathrm{n}=75$ ), an InterStim II IPG was implanted. For all types of stimulators, the median battery life was 6.2 years. A battery change was required in 23 patients (29.1\%). The 5 -year battery (InterStim I and II) survival rate was $76.2 \%$ (95\% CI, 63.8-90.9\%) and the 7-year survival rate was $32.7 \%$ (95\% CI, 19.6-54.5\%). For the InterStim II battery ( $\mathrm{n}=75$ and 23 events), the median survival was 5.9 years (95\% CI, 5.3-6.8 years) with a 7-year survival rate of $25.1 \%$ (95\% CI, 13.0-48.6\%) (Fig. 1B). In all patients, SNM therapy was successfully sustained after a battery change.

\section{Multivariate Analysis of Sacral Neuromodulation Success}

In the univariate analysis, the risk for SNM termination was significantly increased in patients with isolated constipation compared to patients with FI $(P=0.001)$ (Table 3). This association was confirmed in a multivariate analysis with all variables included (full model) and after backward variable selection $(P<0.001)$ (Table 3). In the multivariate analysis, the risk of SNM termination was increased with electrode positioning at $\mathrm{S} 4$ compared to positioning at $\mathrm{S} 3(P=0.042)$.

\section{Symptom Improvement}

Symptom improvement $>50 \%$ was observed in $73.1 \%$ (95\% 
Table 3. Risk Factors for Sacral Neuromodulation Failure

\begin{tabular}{|c|c|c|c|c|c|c|}
\hline \multirow{2}{*}{ Patient characteristics } & \multicolumn{2}{|c|}{ Unadjusted $^{\mathrm{a}}$} & \multicolumn{2}{|c|}{$\begin{array}{l}\text { Cox regression, } \\
\text { full model }\end{array}$} & \multicolumn{2}{|c|}{$\begin{array}{l}\text { Cox regression, } \\
\text { variable selection }^{\mathrm{c}}\end{array}$} \\
\hline & $\mathrm{HR}(95 \% \mathrm{CI})$ & $P$-value ${ }^{\mathrm{d}}$ & $\mathrm{HR}(95 \% \mathrm{CI})$ & $P$-value ${ }^{\mathrm{d}}$ & $\operatorname{HR}(95 \% \mathrm{CI})$ & $P$-value ${ }^{\mathrm{d}}$ \\
\hline Age & $1.01(0.97-1.05)$ & 0.535 & $1.03(0.98-1.08)$ & 0.165 & - & - \\
\hline \multicolumn{7}{|l|}{ Sex } \\
\hline Female & reference & 0.940 & reference & 0.800 & - & - \\
\hline Male & $1.06(0.24-4.66)$ & & $0.82(0.17-3.90)$ & & - & - \\
\hline \multicolumn{7}{|l|}{ Indication } \\
\hline Constipation only & reference & 0.001 & reference & $<0.001$ & reference & $<0.001$ \\
\hline Neurogenic FI & $0.18(0.04-0.92)$ & & $0.11(0.02-0.61)$ & & $0.13(0.03-0.70)$ & \\
\hline Nonneurogenic FI & $0.09(0.03-0.30)$ & & $0.06(0.02-0.21)$ & & $0.08(0.02-0.25)$ & \\
\hline \multicolumn{7}{|l|}{ Lead position } \\
\hline S3 & reference & 0.117 & reference & 0.033 & reference & 0.042 \\
\hline $\mathrm{S} 4$ & $2.13(0.82-5.49)$ & & $2.94(1.08-8.01)$ & & $2.72(1.04-7.15)$ & \\
\hline
\end{tabular}

${ }^{a}$ Univariate Cox regression analysis.

${ }^{\mathrm{b}}$ Multivariable Cox regression analysis full model.

${ }^{c}$ Backward variable selection from the full model confirmed all prognosticators.

${ }^{\mathrm{d}}$ Likelihood ratio tests.

$\mathrm{HR}$, hazard ratio; FI, fecal incontinence; S3, sacral foramina 3; S4, sacral foramina 4.

A

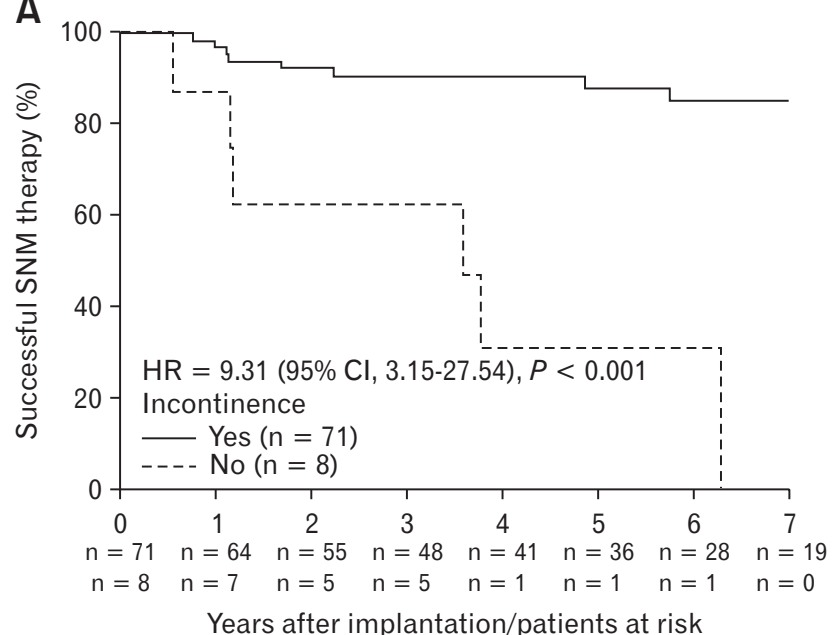

B

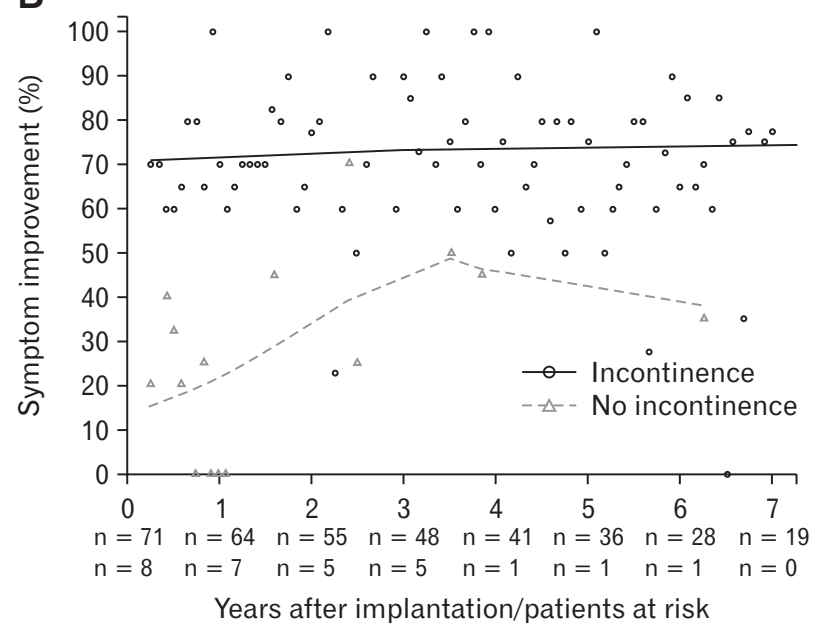

Figure 3. (A) Successful sacral neuromodulation (SNM) therapy. Kaplan-Meier plot comparing patients with or without fecal incontinence (FI). (B) Subjective improvement in patients with isolated constipation and patients with FI shown in a scatter plot (each mark represents an individual patient). Patients who discontinued SNM therapy due to reasons unrelated to SNM therapy were censored. The number of patients at risk is given below each plot for both groups. Hazard ratio (HR) for isolated constipation. $P$-values were estimated with likelihood ratio tests. Patients after permanent implantation were included; no incontinence $=$ isolated constipation .

CI, 66.8-79.5\%) of all patients after one year and $84.3 \%(95 \% \mathrm{CI}$, 64.1-100.0\%) after 7 years.

While for patients with FI the SNM success rate stayed above $80 \%$ for the whole follow-up period, no patient with isolated constipation maintained successful treatment after 6 years (Fig. 3). In patients with FI, several parameters were available to evaluate the effect of SNM therapy. Involuntary evacuations per week decreased
$>50 \%$ in $82.7 \%(95 \% \mathrm{CI}, 76.3-89.1 \%)$ of patients after 1 year and in $78.6 \%$ (95\% CI, 59.1-98.0\%) of patients after 7 years. Figure 4 shows the significant $(P<0.01)$ and lasting improvement in terms of the Wexner score, involuntary evacuations per week and the FIQL questionnaire results. There is a trend towards a more distinct effect of SNM in terms of the Wexner score and involuntary evacuations per week in patients with nonneurogenic FI. For 

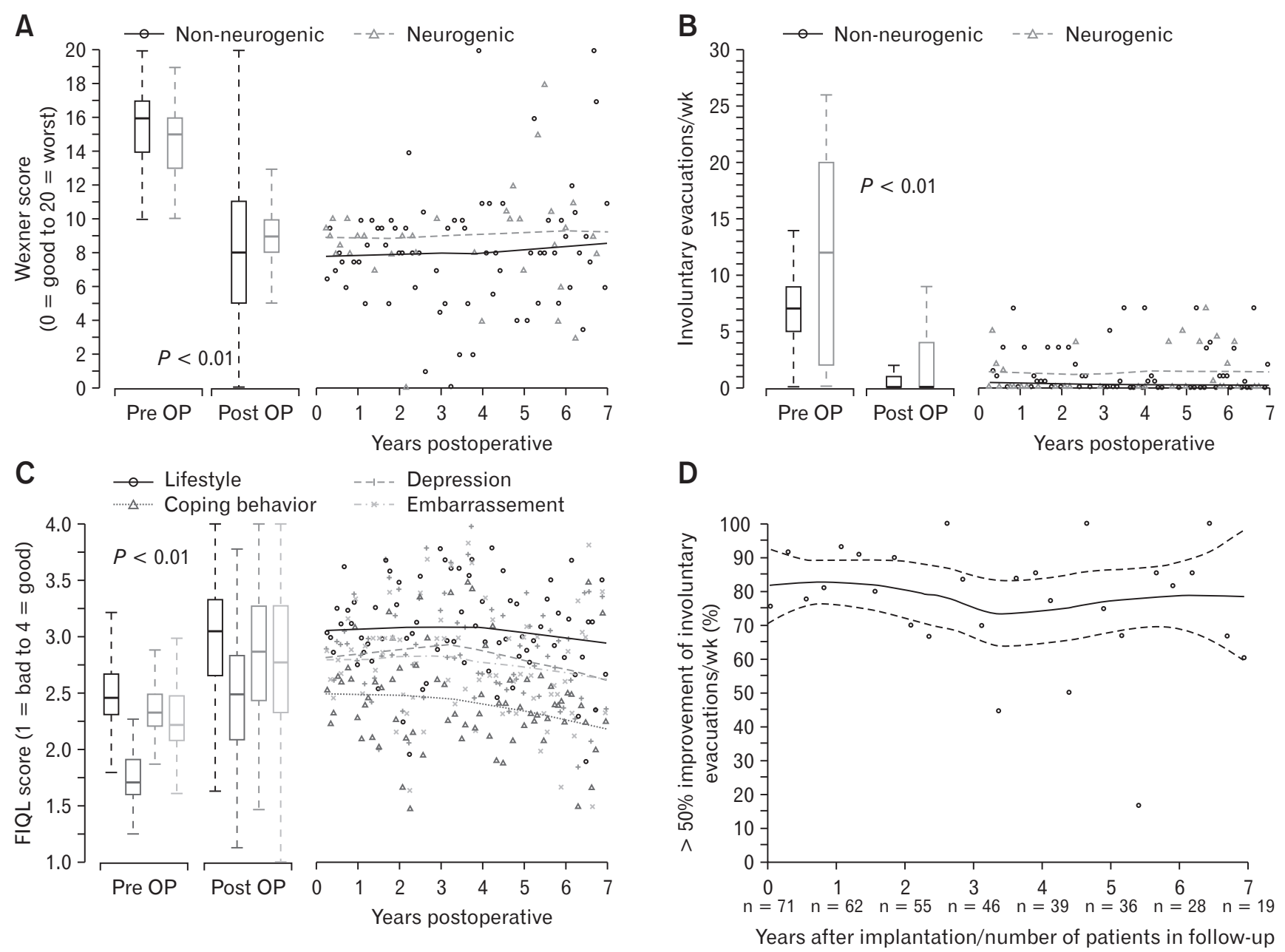

Figure 4. Subjective outcomes (A) change in Wexner scores before and after sacral neuromodulation (SNM) therapy (fecal incontinence [FI] patients only, $\mathrm{n}=71$ ). (B) Change in the number of involuntary evacuations per week (FI patients only, $\mathrm{n}=71$ ). (C) Change in the Fecal Incontinence Quality of Life (FIQL) score (all patients, $\mathrm{n}=79$ ). (D) Percent of patients with $>50 \%$ improvement in involuntary evacuations per week (FI patients only, $\mathrm{n}=71$ ). $P$-values were estimated with the Wilcoxon test. (A-C) left: box plots comparing preoperative (baseline) and postoperative results. (A-C) right and (D): follow-up treatment success of patients with ongoing SNM therapy. OP, operative.

both nonneurogenic and neurogenic FI, the effect of SNM can be sustained over time. There was a significant improvement in patient QoL in all categories of the FIQL (lifestyle, coping/behavior, depression, and embarrassment). In patients with successful SNM therapy, a sustained effect was not only seen in terms of improvement in symptoms but also in terms of QoL.

\section{Complications}

During follow-up, 57 complications occurred in 33 patients $(41.8 \%)$. Of these, 40 complications required surgery in 24 patients (30.4\%), whereas 17 complications in 14 patients (17.7\%) were treated conservatively (Table 4). Some patients had more than one complication. The most common complication was a broken or displaced lead in 22 cases in 16 patients. There were 13 broken leads that all required surgery. Of the 9 cases of lead displacement, all but 2 required surgery. There was no significant association between lead complications and lead position (10 of 43 [23.3\%] for S3 and 6 of 36 [16.7\%] for $\mathrm{S} 4 ; P=0.468$ ) or the side of definitive implantation (4 of 22 [18.2\%] for the left side, 7 of 39 [17.9\%] for the right side, 5 of 18 [27.8\%] for both sides; $P=0.760)$. SNM therapy was discontinued in only one patient after reoperation. This patient had her device removed because of an infection and decided against implantation afterwards. During the screening phase, the complication rate was $6.9 \%$. After SNM implantation, $50.0 \%$ of all complications occurred within 18 months, and $75.0 \%$ occurred within 35 months.

Figure 5 compares the SNM success rates in patients after 
Table 4. Number of Complications, Their Management and Time to First Occurrence in Patients After Sacral Neuromodulation Implantation

\begin{tabular}{lccc} 
Type of complication & $\begin{array}{c}\text { Conservative management } \\
\text { (number of complications) }\end{array}$ & $\begin{array}{c}\text { Surgical management } \\
\text { (number of complications) }\end{array}$ & $\begin{array}{c}\text { Time to complication } \\
\text { after implantation } \\
\text { (mean } \pm \text { SD, days) }\end{array}$ \\
\hline Broken or dislocated lead $(\mathrm{n}=16)$ & 2 & 20 & $898 \pm 873$ \\
Infection $(\mathrm{n}=10)$ & 5 & 5 & $249 \pm 497$ \\
Pain or dysesthesia $(\mathrm{n}=6)$ & 5 & 4 & $859 \pm 687$ \\
IPG dislocation $(\mathrm{n}=5)$ & 1 & 0 & $533 \pm 531$ \\
Constipation $(\mathrm{n}=3)$ & 3 & 3 & $173 \pm 233$ \\
Sudden loss of efficacy & $\mathrm{a}(\mathrm{n}=3)$ & 1 & $485 \pm 379$ \\
\hline
\end{tabular}

${ }^{\mathrm{a}}$ There was no reason found or recorded for the instantaneous loss of effect. IPG, internal permanent pulse generator.

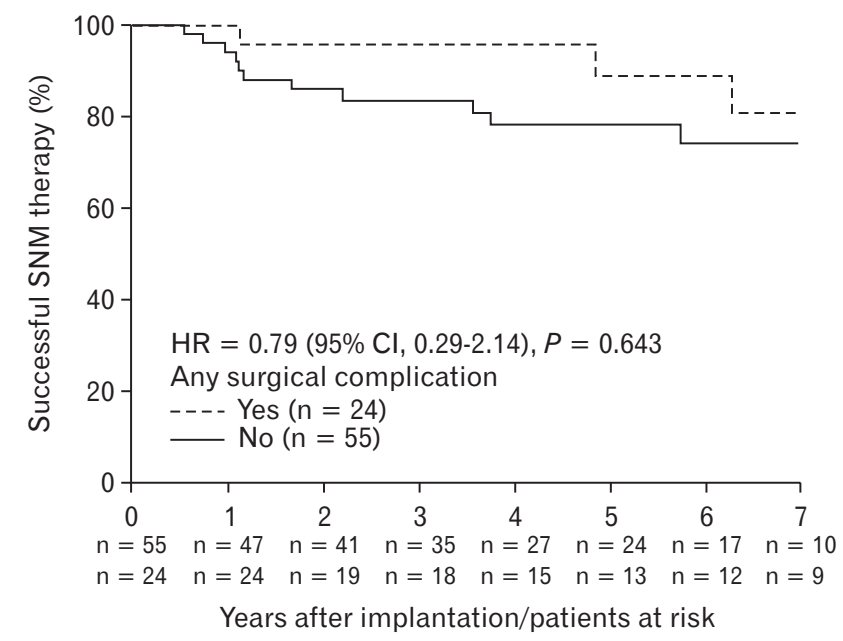

Figure 5. Sacral neuromodulation (SNM) success for patients with and without complications requiring surgery shown in a KaplanMeier plot. Patients who discontinued SNM therapy due to reasons unrelated to the SNM therapy were censored. The number of patients at risk is given below each plot. Hazard ratio (HR) for complications requiring surgery. $P$-values were estimated with likelihood ratio tests. Patients after permanent implantation were included.

IPG implantation with and without complications requiring surgical revisions. The 5-year success rate for patients without any surgical complications was $78.4 \%$ (95\% CI, 67.2-91.4\%) and was $89.0 \%$ (95\% CI, 75.3-100.0\%) for patients with a complication requiring surgical reintervention $(P=0.643)$. At 7 years, the success rates for patients without any surgical complications and those with a complication requiring surgical revision were $74.2 \%$ (95\% CI, 61.6$89.5 \%$ ) and $80.9 \%$ (95\% CI, 62.9-100.0\%), respectively.

\section{Discussion}

This study shows that SNM improves FI in an effective and lasting way. The effect is especially high in patients with both FI and constipation. In contrast, the effect wears off over time in patients with only constipation. Apart from electrode positioning at S3, no other factors could be found to influence the sustainability of SNM success. Surgical reinterventions were necessary in approximately $30 \%$ of patients, but SNM therapy could be maintained successfully. Furthermore, the InterStim II stimulator was found to have a battery life of approximately 6 years.

Successful SNM treatment for patients with FI has been demonstrated in several studies regardless of the cause of FI. ${ }^{13,14,24-26}$ Success rates during the screening phase of $66.8-90.0 \%$ have been reported. ${ }^{12,13,26}$ Recently published reports with follow-up periods of over 36 months have shown that the treatment effect and QoL improvement can be sustained for 5-10 years. ${ }^{12-14}$ A reduction $>50 \%$ in involuntary evacuations per week has been described in $75-84 \%$ of patients. ${ }^{9,27}$ Furthermore, the Wexner score was reduced from 16 to $7,{ }^{26}$ concurrent with significant improvements in all categories of the FIQL. ${ }^{9,13}$ These results were confirmed by this study. In a systematic review from 2013 involving 61 eligible studies analyzing the effectiveness of neuromodulation in FI, most studies had only short- or midterm follow-up periods. ${ }^{9}$ The median number of patients in trials with long-term follow-up was 21 (range: 9-91). Long-term follow-up studies with a high number of patients are scarce. The largest recent multicenter study by Altomare et $\mathrm{al}^{26}$ included 228 patients. In that study and in the systematic review mentioned before, the success rates based on ITT were $48 \%$ and $54 \%$, respectively, compared to the 5 -year ITT success rate for FI of $70 \%$ in this study. The reasons for this superior result are unclear but might be explained by the rigorous follow-up and the consequent maintenance interventions.

This seems to be the first study to assess the sustainability of SNM success by including patients with constipation and FI. The 
role of SNM for constipated patients is currently debated. This study and 2 other studies showed no difference in the outcome of SNM therapy in different subtypes of constipation. Nevertheless, in all studies, there were relatively few cases. ${ }^{28,29}$ A European consensus paper stated that further trials are needed and that this therapy is less effective for constipation than for $\mathrm{FI} .{ }^{15}$ Overall, the reported results are rather disappointing, although midterm success rates of up to $90 \%$ have been shown after permanent SNM implantation. ${ }^{30}$ Furthermore, SNM therapy was effective for constipation in a double-blind crossover trial in which placebo effects could be ruled out. ${ }^{31}$ However, a larger similar randomized controlled trial showed no effect on constipation, whether the stimulation was active or not. $^{32}$ There are hardly any long-term results. A recent long-term study following 45 constipated patients after permanent implantation found that on average constipation symptoms were improved in the 18 patients available at a 5 -year follow-up. ${ }^{29}$ This analysis observed a significantly lower success rate in the percutaneous nerve evaluation and in the sustainability of SNM success in patients with isolated constipation. In all patients with isolated constipation, SNM therapy was terminated during follow-up. In patients with both constipation and FI, the therapeutic success was significantly $(P=0.041)$ better than in patients with $\mathrm{FI}$ alone. One possible explanation is that the effect of SNM therapy accumulates because the symptoms of both FI and constipation improve. This is most likely if the symptoms have a common origin. It is known that rectal hyposensitivity is seen in patients with FI and constipation. ${ }^{33}$ SNM therapy can normalize the rectal sensory threshold in patients with rectal hyposensitivity and reduce symptoms effectively. ${ }^{34}$

In addition to the indications for SNM therapy, this trial identified only lead positioning at S3 as a factor for success. The S3 nerve contains efferent and afferent fibers from the anterior part of the levator ani and sensory fibers from the perineum and the genitals. Stimulation at S2 and occasionally at the level of S3 might result in muscle cramping in the legs. ${ }^{35,36} \mathrm{~S} 4$ affects the posterior part of the levator ani with sensation around the anus and has no motor effects on the legs. ${ }^{37}$ Currently, there is no recommendation regarding whether the $\mathrm{S} 3$ or the $\mathrm{S} 4$ foramen should be preferred. ${ }^{15}$ To our knowledge, only one other study has analyzed the influence of S3 vs S4 electrode placement on success. ${ }^{38}$ This study showed no difference in the effect on incontinence. However, the proportion of patients implanted at $\mathrm{S} 4$ was minor, and no multivariate analysis was performed. In accordance with other authors, no other predictors of success were found. The cause of FI and the extent of sphincter lesions do not seem to limit treatment success. ${ }^{26,39,40}$

Several reinterventions were due to expected maintenance rath- er than to adverse events. Since rechargeable batteries are expensive and need a long recharging time, they are not yet used routinely. All patients with nonrechargeable IPGs need a battery change after a number of years. Using Kaplan-Meier analysis, we determined that median battery life of the InterStim II IPG was 5.9 years, which corresponds well with the results of a smaller study reporting a mean battery life of 5.4 years; however, that study did not indicate the type of stimulator that was used. ${ }^{19}$ Another larger study included InterStim I IPGs and the Kaplan-Meier curve for the InterStim II IPG did not reach the $50 \%$ threshold to calculate the median battery life. By extrapolation, a median survival of approximately 6.5 years might be expected. ${ }^{41}$ For the InterStim I stimulator, a median lifespan of 8.8 years was found. Otherwise, relatively little data are available on battery life. The expected battery life is essential to estimate the maintenance effort and the cost required to sustain SNM therapy. This might impact the decision regarding which IPG type fits each individual patient. In accordance with the previously mentioned study, this trial showed that SNM therapy is still successful after replacing the IPG. ${ }^{41}$

It is challenging to evaluate adverse events and reinterventions, since most events occur several years after implantation. Most studies have focused on the efficacy of SNM therapy, and many did not describe adverse events in detail. A recent literature review showed a wide variation in adverse events. ${ }^{18}$ In one study with detailed information on adverse events, a complication rate of $93 \%$ over a period of 5 years was reported. ${ }^{42}$ In the long-term follow-up of an American multicenter study on SNM, 26.3\% of SNM patients required reoperation to treat adverse events excluding battery changes. ${ }^{43} \mathrm{~A}$ British study reported reoperations in $28.8 \%$ of their patients after a shorter follow-up period. ${ }^{19}$ This analysis shows that, in most cases, SNM therapy can be sustained by reinterventions. In many cases, adverse events such as infections or IPG dislocation can be successfully managed. Lead replacement led to a worse treatment effect in a recent study, ${ }^{44}$ while in the present study, the success rate after surgical revision was at least as good as that in patients without revision.

In the following the strengths and limitations of the study are discussed. This study is one of the largest single-center follow-up analyses evaluating the sustainability of SNM success. Furthermore, this study included patients with FI and constipation.

A limitation of the study is the retrospective nature, which presents a certain risk of bias. There were relatively few patients with constipation alone. However, reports on constipation with a higher caseload are rare, especially those with mid- and long-term follow-up periods. Furthermore, the treatment success in patients with constipation could only be assessed by subjective improvement in symptoms. 
In conclusion, this study shows that SNM is an effective and sustainable treatment for FI regardless of its etiology. The outcome of SNM is even better when FI is accompanied by constipation. In patients with isolated constipation, the initial success rate is low and decreases over time. Therefore, the indications for SNM therapy should be restrained in patients with isolated constipation. Additionally, a lead position at S3 led to improved outcomes and should be preferred to $\mathrm{S} 4$ positioning if the response to stimulation is similar during nerve evaluation. Adverse events are common, and reinterventions must be expected in the long term. However, such reoperations are worthwhile as they sustain the treatment success. Before beginning SNM therapy, patients should be informed about the necessity for long-term follow-up, the possibility of operative revisions and the need for a battery change after 5-7 years.

Acknowledgement: The authors thank Lydia Widmann and Robert Miner for English language editing and Jana Szabó and Cornelia Lüthi, the study nurses of the Department of General, Visceral, Endocrine and Transplantation Surgery at the Kantonsspital St. Gallen, for their contribution to data collection.

Financial support: We used the registry for sacral neuromodulation of the Swiss Society of Sakral neuromodulation. This registry is sponsered by Medtronic. There was no direct funding of this analysis/manuscript.

Conflicts of interest: Bernhard Widmann, Christian Galata, Rene Warschkow, Ulrich Beutner, Önder Ögredici, Bruno M Schmied, and Stefan Post have no conflicts of interest or financial ties to disclose. Franc H Hetzer was a consultant for Medtronic. Lukas Marti received partial funding for an international pelvic floor fellowship by Medtronic 7 years ago. Furthermore, he is conducting workshops on operative hemorrhoid treatment, for which the institution in which he is working receives some financial compensation from Medtronic. As products manufactured by Medtronic are needed to conduct the therapy described here, this might be seen as a possible conflict of interest. Furthermore, the partial funding of the Swiss Registry of Neuromodulation, which has been used to conduct this analysis, might also be seen as such.

Disclosures: The data were obtained from the Swiss Registry of Sacral Neuromodulation. The development of this registry, its maintenance, data input and data attainment were supported partly by Medtronic. This study was not sponsored or influenced in any way by Medtronic. Only data from patients treated at the Depart- ment of General, Visceral, Endocrine and Transplantation Surgery of the Kantonsspital St. Gallen have been included.

Author contributions: Study conception and design: Bernhard Widmann, Rene Warschkow, and Lukas Marti; acquisition of data: Bernhard Widmann, Rene Warschkow, Önder Ögredici, Franc $\mathrm{H}$ Hetzer, and Lukas Marti; analysis and interpretation of data: Bernhard Widmann, Christian Galata, Rene Warschkow, Ulrich Beutner, Önder Ögredici, Franc H Hetzer, Bruno M Schmied, Stefan Post, and Lukas Marti; drafting the article: Bernhard Widmann, Rene Warschkow, and Lukas Marti; critical revision of the manuscript: Bernhard Widmann, Christian Galata, Rene Warschkow, Ulrich Beutner, Franc H Hetzer, Bruno M Schmied, Stefan Post, and Lukas Marti; final approval of the version to be published; and Bernhard Widmann, Christian Galata, Rene Warschkow, Ulrich Beutner, Önder Ögredici, Franc H Hetzer, Bruno M Schmied, Stefan Post, and Lukas Marti.

\section{References}

1. Ng KS, Sivakumaran Y, Nassar N, Gladman MA. Fecal incontinence: community prevalence and associated factors-a systematic review. Dis Colon Rectum 2015;58:1194-1209.

2. Stewart WF, Liberman JN, Sandler RS, et al. Epidemiology of constipation (EPOC) study in the United States: relation of clinical subtypes to sociodemographic features. Am J Gastroenterol 1999;94:3530-3540.

3. Everhart JE, Ruhl CE. Burden of digestive diseases in the United States part II: lower gastrointestinal diseases. Gastroenterology 2009;136:741754

4. Ganio E, Masin A, Ratto C, et al. Short-term sacral nerve stimulation for functional anorectal and urinary disturbances: results in 40 patients: evaluation of a new option for anorectal functional disorders. Dis Colon Rectum 2001;44:1261-1267.

5. Matzel KE, Stadelmaier U, Hohenfellner M, Gall FP. Electrical stimulation of sacral spinal nerves for treatment of faecal incontinence. Lancet 1995;346:1124-1127.

6. Rosen HR, Urbarz C, Holzer B, Novi G, Schiessel R. Sacral nerve stimulation as a treatment for fecal incontinence. Gastroenterology 2001;121:536-541.

7. Gourcerol G, Vitton V, Leroi AM, Michot F, Abysique A, Bouvier M. How sacral nerve stimulation works in patients with faecal incontinence. Colorectal Dis 2011;13:e203-e211.

8. Sheldon R, Kiff ES, Clarke A, Harris ML, Hamdy S. Sacral nerve stimulation reduces corticoanal excitability in patients with faecal incontinence. Br J Surg 2005;92:1423-1431.

9. Hotouras A, Murphy J, Thin NN, et al. Outcome of sacral nerve stimulation for fecal incontinence in patients refractory to percutaneous tibial nerve stimulation. Dis Colon Rectum 2013;56:915-920.

10. Tjandra JJ, Chan MK, Yeh CH, Murray-Green C. Sacral nerve 
stimulation is more effective than optimal medical therapy for severe fecal incontinence: a randomized, controlled study. Dis Colon Rectum 2008;51:494-502.

11. Wexner SD, Coller JA, Devroede G, et al. Sacral nerve stimulation for fecal incontinence: results of a 120-patient prospective multicenter study. Ann Surg 2010;251:441-449.

12. Hollingshead JR, Dudding TC, Vaizey CJ. Sacral nerve stimulation for faecal incontinence: results from a single centre over a 10-year period. Colorectal Dis 2011;13:1030-1034.

13. Mellgren A, Wexner SD, Coller JA, et al. Long-term efficacy and safety of sacral nerve stimulation for fecal incontinence. Dis Colon Rectum 2011;54:1065-1075.

14. Altomare DF, Ratto C, Ganio E, Lolli P, Masin A, Villani RD. Longterm outcome of sacral nerve stimulation for fecal incontinence. Dis Colon Rectum 2009;52:11-17.

15. Maeda Y, O'Connell PR, Lehur PA, Matzel KE, Laurberg S; European SNS Bowel Study Group. Sacral nerve stimulation for faecal incontinence and constipation: a European consensus statement. Colorectal Dis 2015;17:O74-O87.

16. Thaha MA, Abukar AA, Thin NN, Ramsanahie A, Knowles CH. Sacral nerve stimulation for faecal incontinence and constipation in adults. Cochrane Database Syst Rev 2015;8:CD004464.

17. Bielefeldt K. Adverse events of sacral neuromodulation for fecal incontinence reported to the federal drug administration. World J Gastrointest Pharmacol Ther 2016;7:294-305.

18. Maeda Y, Matzel K, Lundby L, Buntzen S, Laurberg S. Postoperative issues of sacral nerve stimulation for fecal incontinence and constipation: a systematic literature review and treatment guideline. Dis Colon Rectum 2011;54:1443-1460.

19. Zeiton M, Faily S, Nicholson J, Telford K, Sharma A. Sacral nerve stimulation-hidden costs (uncovered). Int J Colorectal Dis 2016;31:1005-1010.

20. Jorge JM, Wexner SD. Etiology and management of fecal incontinence. Dis Colon Rectum 1993;36:77-97.

21. Rockwood TH, Church JM, Fleshman JW, et al. Fecal incontinence quality of life scale: quality of life instrument for patients with fecal incontinence. Dis Colon Rectum 2000;43:9-16; discussion 16-17.

22. Ishwaran H, Kogalur UB, Blackstone EH, Lauer MS. Random survival forests. Ann Appl Stat 2008;2:841-860.

23. Cleveland WS. Robust locally weighted regression and smoothing scatterplots. J Am Stat Assoc 1979;74:829-836.

24. Boyle DJ, Knowles CH, Lunniss PJ, Scott SM, Williams NS, Gill KA. Efficacy of sacral nerve stimulation for fecal incontinence in patients with anal sphincter defects. Dis Colon Rectum 2009;52:1234-1239.

25. Ramage L, Qiu S, Kontovounisios C, Tekkis P, Rasheed S, Tan E. A systematic review of sacral nerve stimulation for low anterior resection syndrome. Colorectal Dis 2015;17:762-771.

26. Altomare DF, Giuratrabocchetta $\mathrm{S}$, Knowles $\mathrm{CH}$, et al. Long-term outcomes of sacral nerve stimulation for faecal incontinence. Br J Surg 2015;102:407-415.

27. Duelund-Jakobsen J, van Wunnik B, Buntzen S, Lundby L, Baeten C, Laurberg S. Functional results and patient satisfaction with sacral nerve stimulation for idiopathic faecal incontinence. Colorectal Dis 2012;14:753-759.
28. Graf W, Sonesson AC, Lindberg B, Åkerud P, Karlbom U. Results after sacral nerve stimulation for chronic constipation. Neurogastroenterol Motil 2015;27:734-739.

29. Maeda Y, Kamm MA, Vaizey CJ, et al. Long-term outcome of sacral neuromodulation for chronic refractory constipation. Tech Coloproctol 2017;21:277-286.

30. Govaert B, Maeda Y, Alberga J, Buntzen S, Laurberg S, Baeten CG. Medium-term outcome of sacral nerve modulation for constipation. Dis Colon Rectum 2012;55:26-31.

31. Kenefick NJ, Vaizey CJ, Cohen CR, Nicholls RJ, Kamm MA. Doubleblind placebo-controlled crossover study of sacral nerve stimulation for idiopathic constipation. Br J Surg 2002;89:1570-1571.

32. Dinning PG, Hunt L, Patton V, et al. Treatment efficacy of sacral nerve stimulation in slow transit constipation: a two-phase, double-blind randomized controlled crossover study. Am J Gastroenterol 2015;110:733740 .

33. Burgell RE, Scott SM. Rectal hyposensitivity. J Neurogastroenterol Motil 2012;18:373-384.

34. Knowles CH, Thin N, Gill K, et al. Prospective randomized doubleblind study of temporary sacral nerve stimulation in patients with rectal evacuatory dysfunction and rectal hyposensitivity. Ann Surg 2012;255:643-649.

35. Dijkema HE, Weil EH, Mijs PT, Janknegt RA. Neuromodulation of sacral nerves for incontinence and voiding dysfunctions. Clinical results and complications. Eur Urol 1993;24:72-76.

36. Schmidt RA, Senn E, Tanagho EA. Functional evaluation of sacral nerve root integrity. Report of a technique. Urology 1990;35:388-392.

37. Dudding TC, Hollingshead JR, Nicholls RJ, Vaizey CJ. Sacral nerve stimulation for faecal incontinence: optimizing outcome and managing complications. Colorectal Dis 2011;13:e196-e202.

38. Patton V, Abraham E, Lubowski DZ. Sacral nerve stimulation for faecal incontinence: medium-term follow-up from a single institution. ANZ J Surg 2017;86:462-466.

39. Gourcerol G, Gallas S, Michot F, Denis P, Leroi AM. Sacral nerve stimulation in fecal incontinence: are there factors associated with success? Dis Colon Rectum 2007;50:3-12.

40. Roy AL, Gourcerol G, Menard JF, Michot F, Leroi AM, Bridoux V. Predictive factors for successful sacral nerve stimulation in the treatment of fecal incontinence: lessons from a comprehensive treatment assessment. Dis Colon Rectum 2014;57:772-780.

41. Duchalais E, Meurette G, Perrot B, Wyart V, Kubis C, Lehur PA. Exhausted implanted pulse generator in sacral nerve stimulation for faecal incontinence: what next in daily practice for patients? Int J Colorectal Dis 2016;31:439-444.

42. Maeda Y, Lundby L, Buntzen S, Laurberg S. Outcome of sacral nerve stimulation for fecal incontinence at 5 years. Ann Surg 2014;259:11261131.

43. Hull T, Giese C, Wexner SD, et al. Long-term durability of sacral nerve stimulation therapy for chronic fecal incontinence. Dis Colon Rectum 2013;56:234-245.

44. Cracco AJ, Chadi SA, Rodrigues FG, et al. Outcomes of sacral neurostimulation lead reimplantation for fecal incontinence: a cohort study. Dis Colon Rectum 2016;59:48-53. 